\title{
Protective effect of some natural products on acrylamide induced toxicity
}

\author{
Kadry A. El-Bakry ${ }^{1}$, Gamal A. Abd-Allah ${ }^{1}$, Mohamed H. Bahnasawy ${ }^{1}$, Lotfy Z. Habbak ${ }^{1}$, Fayzah A. Aboubakr*2 \\ 1 Zoology Department, Damietta Faculty of Science, Damietta, Egypt. \\ ${ }^{2}$ Zoology Department, Sebha University, Libya.
}

Received: 21 March 2016/ Accepted: 18 June 2016

*Corresponding author: faizaahmad33@yahoo.com

\begin{abstract}
The present study was carried out to investigate the hematological and immunological effects of acrylamide on immature male and female rats. The roles of honey and/or nigella sativa oil treatment against these effects of ACR were also investigated. Acrylamide (ACR) is a well-known industrial toxic chemical that produces neurotoxicity, which is characterized by progressive central and peripheral neuronal degeneration. There was significant decrease in the hemoglobin content $(\mathrm{p}<$ $0.05)$ and RBCS counts $(\mathrm{p}<0.05)$ and significant increase in WBCS $(\mathrm{p}<0.05)$ and platelets counts $(\mathrm{p}<0.01)$ due to acrylamide toxicity. At recovery period, there was significant increase in the hemoglobin content and RBCS counts of honey and/or Nigella sativa oil-treated groups as compared to those of the untreated rats but they were still significantly lower than those of the control rats. Moreover, there was significant decrease in the WBCs and platelets counts of honey and/or Nigella sativa oil -treated groups of animals as compared to those of the untreated toxicated rats. In addition, there were significant decreases in the levels of both tumor necrosis factor (TNF-alpha) and Interleukin-17 (IL-17) in this study due to ACR toxicity. At recovery period, there were significant increases in the in the levels of both TNF-alpha and IL-17 of honey and/or Nigella sativa oil -treated groups of animals as compared to those of the untreated toxicated rats. In the current study, the treatments with honey and/or Nigella sativa oil enhance the hematological and immunological parameters of the treated animals that can participate in the neuroprotective effect of Acrylamide on Wistar rats.
\end{abstract}

Keywords: Acrylamide, Honey, Nigella Sativa, Neurotoxicity, Rats.

\section{Introduction}

Acrylamide or 2-propenamide an industrial chemical formed in some foods particularly starchy foods during heating process such as baking, frying and roasting. Acrylamide is proven to be carcinogenic in animals and a probable human carcinogen mainly formed in foods by the reaction of asparagine (free amino acid) with reducing sugars (glucose and fructose) as part of the Maillard reaction during heating under high temperature and low moisture conditions (Krishnakumar and Visvanathan, 2014).

Also Acrylamide (ACR) has been shown to cause neurotoxic effects in humans and neurotoxic, genotoxic, reproductive and carcinogenic effects in laboratory animals Keivanand Afshin, 2015) 
Honey is naturally occurring substance contains a highly concentrated mixture of simple and complex sugars in syrupy solution (Gheldofet al., 2002). Honey mainly consists of sugars and water. Sugars in honey comprises predominantly of monosaccharides and oligosaccharides the most abundant sugar in honey is fructose, while sugars in it are sweeter and give more energy than artificial sweeteners (White and Doner,1980; Ajibolaet al 2012 ). Apart from sugars, honey also contains several vitamins, especially B complex and vitamin $\mathrm{C}$, together with a lot of minerals. Some of the vitamins found in honey include ascorbic acid, pantothenic acid, niacin and riboflavin; while minerals such as calcium, copper, iron, magnesium, manganese, phosphorus, potassium and zinc are also present (Ajibola et al., 2012). Generally, honey contains at least 181 constituents (Bogdanovet al., 2008; Gheldofet al., 2002). The other constituents of honey are amino acids, antibiotic-rich inhibine, proteins and phenol antioxidants (Wang, 2011). It also contains other bioactive substances such as phenolic constituents, flavonoids, organic acids, carotenoid-derived compounds, nitric oxide (NO) metabolites, amino acids and proteins (Arriaga et al., 2011; Beretta et al., 2010).

Nigella sativus is an annual flowering plant belongs to the family Ranunculaceae. It is cultivated mainly in countries bordering the Mediterranean Sea middle Europe and western Asia (Rchid et al., 2004). It contains a complex mixture of more than 100compounds (Salih et al., 2009). Most of the therapeutic properties of Nigella sativa oil aredue to the presence of thepolyphenol Thymoquinone

Thymoquinone, the major component of the essential oil, is the biologically active gradient of this plant. It was reported that, thymoquinone (TQ) has many medicinal properties like; antioxidant anti-inflammatory, anti-tumor, analgesic and other properties (Ahmad et al., 2013)which is the major component (28-57\%) of Nigella sativa oil(Ali and Blunden, 2003)In addition, there are many fatty acids, proteins, alkaloids, and saponin.(Al-Logmani and Zari, 2011)

Tumor necrosis factor TNF is a member of a family of structurally related Cytokines that signal through specific cell-surface receptors that also forma structurally related family of proteins. One of multiple proteins capable of inducing necrosis (death) of tumor cells that possess a wide range of proinflammatory actions. Abbreviated TNF. TNF is a multifunctional cytokine with effects on lipid metabolism, coagulation, insulin resistance, and the function of endothelial cells lining blood vessels. Drugs that block the action of TNF have been shown to be beneficial in reducing the inflammation in inflammatory diseases such as Crohn's disease and rheumatoid arthritis (Ware CF, 2003)

Interleukin-17 (IL-17) has emerged as a central player in the mammalian immune system. Although this cytokine exerts a host-defensive role in many infectious diseases, it promotes inflammatory pathology in autoimmunity and other settings. A myriad of studies have focused on how IL-17-producing cells are generated. However, the means by which IL-17 achieves its effects, either for the benefit or the detriment of the host, are due in large part to the induction of new gene expression. Whereas many IL-17 target genes are common to different disease states, in some cases the effects of IL-17 differ depending on the target cell, infectious site or pathogen. Gene products induced by IL-17 include cytokines (IL6 , granulocyte-colony-stimulating factor, tumour necrosis factor- $\alpha$ ), chemokines (CXCL1, CXCL2, CCL20, among many others), inflammatory effectors (acute-phase protesins, complement) and antimicrobial proteins (defensins, mucins). Different cell types appear to respond differently to IL-17 in terms of target gene expression, with notable differences seen in mesenchymal and epithelial cells compared with cells of haematopoietic origin. Here, we summarize the major IL-17 target genes that mediate this cytokine's activities in both autoimmune and chronic diseases as well as during various types of infections.

\section{MATERIALS AND METHODS}

\section{Experimental animals}

Wister albino rats (Male and Female rats weighing about $80-120 \mathrm{~g}$ ) were purchased from the experimental animal care center of EGY VACHelwan animal station. Animals were maintained on standard diet and housed, in polystyrene cages in room free from any source of chemical contamination, artificially illuminated $(12 \mathrm{~h}$ dark/light cycle) and thermally controlled (25 $2^{\circ} \mathrm{C}$ ). All animals received humane care in compliance with the guidelines of the Ethics committee. Experiments were started after the animals were allowed to adapt for four weeks. 


\section{Experimental design}

Rats were divided randomly into 5 groups as follow:-

G1: control group, include 6 males and 6 females in separate cages were fed in normal diet.

G2: Acrylamide group, include 7 males and 7 females separately and were administered daily acrylamide in drinking water $(50 \mathrm{mg} / \mathrm{kg}$ body weight) for 4 weeks.

G3: Acrylamide and honey group, include 7 males and 7 females separately. Acrylamide was administered daily in drinking water as the above and honey was daily in drinking water for 4 weeks. G4: Acrylamide and Nigella sativa group, include 7 males and 7 females separately. Nigella sativa was administered daily using stomach tube $(2.5 \mathrm{ml} / \mathrm{kg}$ body weight $)$ for 4 weeks. Acrylamide was administered in drinking water as in the second group.

G5: Acrylamide, honey and nigella sativa group, include 7 males and 7 females separately. Acrylamide, honey and Nigella sativa satin were administered as the previous groups.

\section{Methods}

\section{I-Hematological study}

Determination of the parameters of the complete blood picture were done by Sysmex the automatic hematology analyzer SF - 3000, corporation KOBE. JAPAN.

\section{II-Immunological studies}

\section{Tumor necrosis factor-alpha (TNF-alpha)}

The method was done according to the manufacture instruction of Assaypro.uk.

\section{Principle-:}

The Assay Max Rat Tumor Necrosis Factor- $\alpha$ ELISA (Enzyme- linked immunosorbent Assay) kit is designed for detection of TNF- $\alpha$ in rat cell culture supernatants and other body fluids including serum. This assay employs a quantitative sandwich enzyme immunoassay technique that measures TNF- $\alpha$ in less than 5 hours. A murine monoclonal antibody specific for rat TNF- $\alpha$ has been pre-coated onto a 96- well microplate with removable strips. TNF- $\alpha$ in standards and samples is sandwiched by the immobilized antibody and a biotinylated polyclonal antibody specific for rat TNF- $\alpha$, which is recognized by a streptavidin- peroxidase conjugate. All unbound material was then washed away and a peroxidase enzyme substrate is added. The color development was stopped and the intensity of the color was measured.

\section{Interleukin $17(I L-17)$}

The method was done according to the manufacture instruction of CUSABIO. (China)

\section{Principle of the assay}

This assay employs the quantitative sandwich enzyme immunoassay technique. Antibody specific for IL-17 has been pre-coated onto a microplate. Standards and samples are pipette into the wells and any IL-17 present is bound by the immobilized antibody. After removing any unbound substances, a biotin-conjugated antibody specific for IL-17 is added to the wells. After washing, avidin conjugated Horseradish peroxidase (HRP) is added to the wells. Following a wash to remove any unbound avidin-enzyme reagent, a substrate solution is added to the wells and color develops in proportion to the amount of IL-17 bound in the initial step .The color development was stopped and the intensity of the color was then measured.

\section{Results}

\section{Hematological study}

In the hematological study, the mean of hemoglobin content, WBCS, RBCS and platelets in rats drinking acrylamide and treated with honey and/or nigella sativa oil were evaluated(figures $1,2,3$ and 4). There was a significant decrease in the hemoglobin content $(\mathrm{p}<0.05)$ and RBCS ( $\mathrm{p}<$ 0.05).After treatment there was significant increase in the hemoglobin content and RBCS of honey and/or Nigella sativa oil -treated groups as compared to untreated rats but, were significantly lower than control rats. 


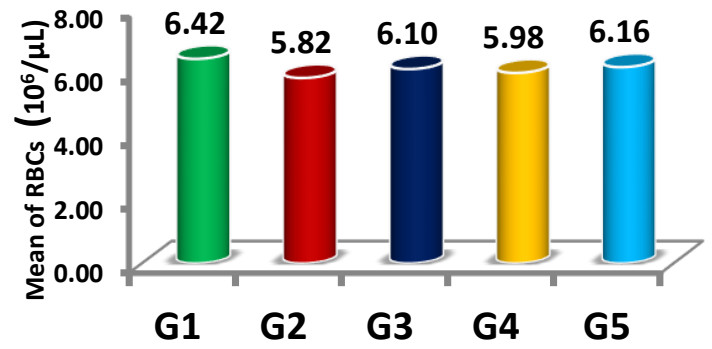

Figure (1): Mean number of RBCs $\left(10^{6} / \mu 1\right)$ in rats drinking Acrylamide (50mg $/ \mathrm{kg}$ body weight) and rats drinking Acrylamide treated with honey $(10 \%(w / w)$ and / or nigella sativa oil ( $2.5 \mathrm{ml} / \mathrm{kg}$ body weight). There was no significant difference among all groups $(\mathrm{p}>0.05)$

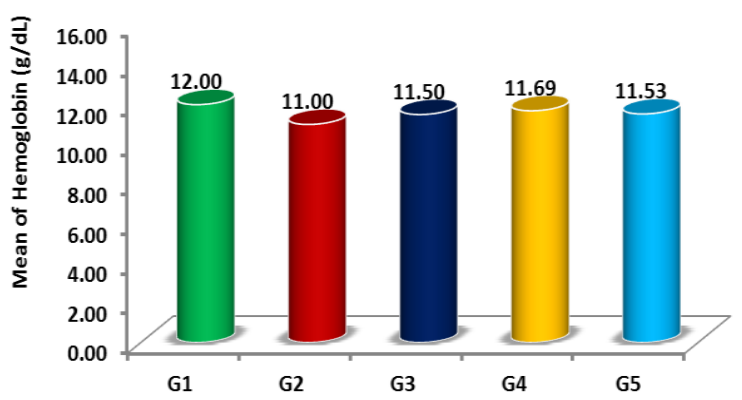

Figure (2): Mean of Hemoglobin content (g/dl) in rats drinking Acrylamide (50mg $/ \mathrm{kg}$ body weight) and rats drinking Acrylamide treated with honey $(10 \%(\mathrm{w} / \mathrm{w})$ and / or nigella sativa oil $(2.5 \mathrm{ml} / \mathrm{kg}$ body weight $)$.

There was no significant difference among all groups $(\mathrm{p}>0.05)$. There was significant increase in WBCS $(\mathrm{p}<0.05)$ and platelets count $(\mathrm{p}<0.01)$ due to acrylamide toxicity compared with normal group there was significant decrease in the WBCS and platelets count of honey and/or Nigella sativa oil -treated groups of animals as compared to untreated toxicated rats.

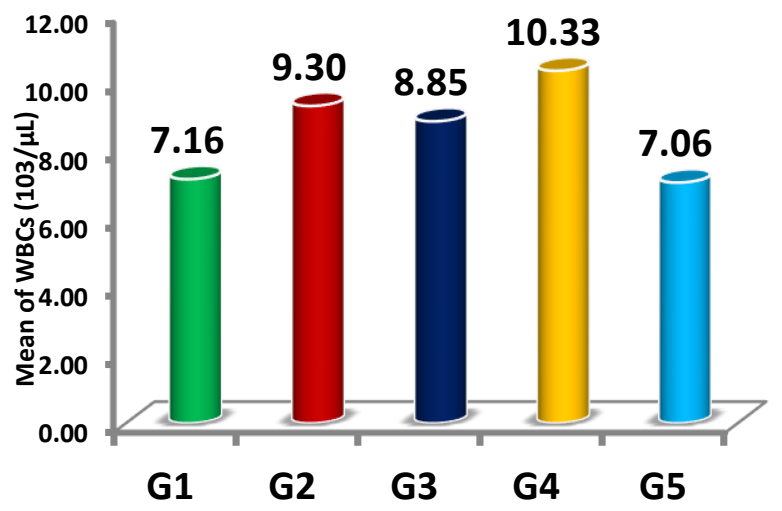

Figure (3): Mean of WBCs (103/ $\mu 1)$ in rats drinking Acrylamide (50mg $/ \mathrm{kg}$ body weight) and treated with honey $(10 \%(\mathrm{w} / \mathrm{w})$ and / or nigella sativa oil $(2.5 \mathrm{ml} / \mathrm{kg}$ body weight). There is significant difference among the groups of the present study. $(\mathrm{p}<0.05)$

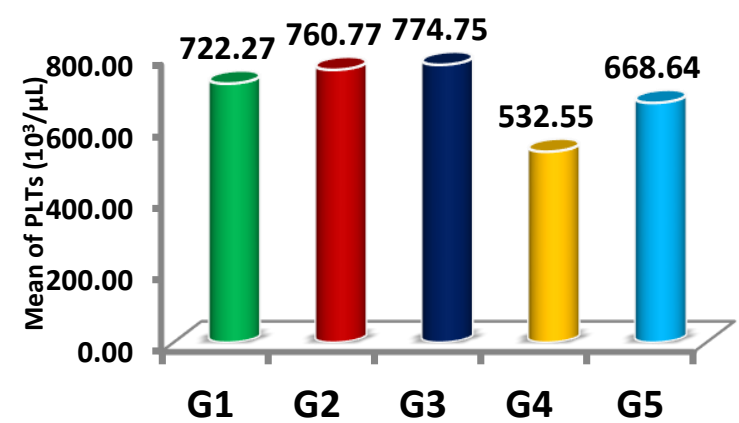

Figure (4): Mean of PLTs $\left(10^{3} / \mathrm{\mu l}\right)$ in rats drinking Acrylamide $(50 \mathrm{mg} / \mathrm{kg}$ body weight) and treated with honey $(10 \%(\mathrm{w} / \mathrm{w})$ and / or nigella sativa oil $(2.5 \mathrm{ml} / \mathrm{kg}$ body weight). There was a highly significant difference between the groups of the present study, $(p<0.01)$.

\section{Immunological study:}

The present study showed that, there was significant decrease in the Tumor Necrosis Factor (TNF-alpha) and Interleukin-17 (IL-17) (Fig. 5 and 6) due to acrylamide toxicity. However, after treatments with honey and/or Nigella sativa oil, there was significant increase in the TNF-alpha and IL-17 of honey and/or Nigella sativa oil treated groups of animals as compared to untreated toxicated rats.

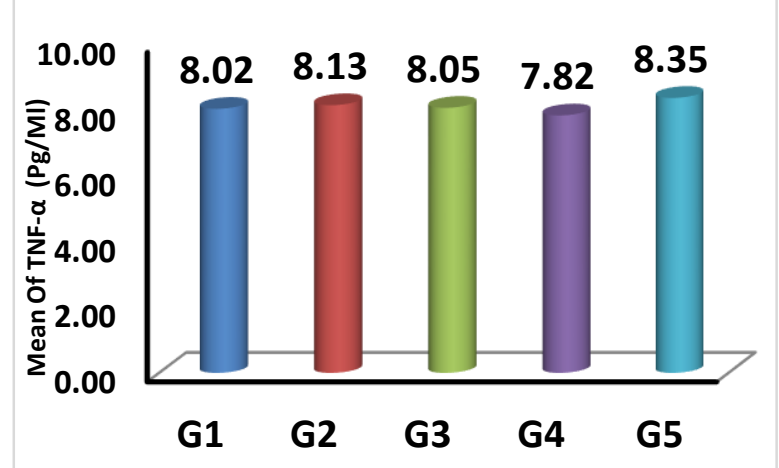

Figure (5) Mean of TNF- $\alpha(\mathrm{pg} / \mathrm{ml})$ in rats drinking Acrylamide $(50 \mathrm{mg} / \mathrm{kg}$ body weight) and treated with honey $(10 \%(\mathrm{w} / \mathrm{w})$ and / or nigella sativa oil $(2.5 \mathrm{ml} / \mathrm{kg}$ body weight). Statistical analysis (one-way ANOVA) indicated that, there was no significant difference $(\mathrm{p}>$ $0.05)$ among all groups. 


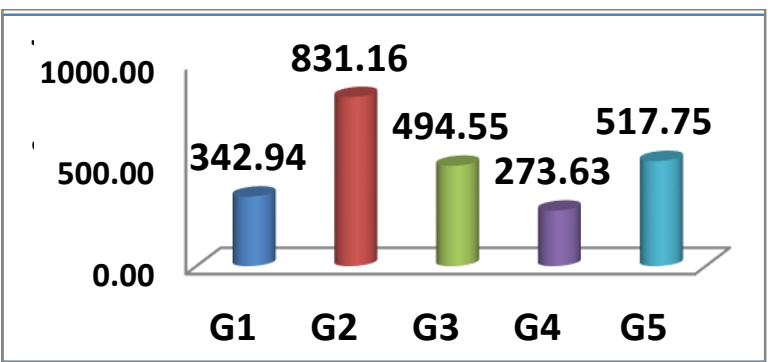

Figure (6) Mean of IL-17 (pg/ml) in rats drinking Acrylamide $(50 \mathrm{mg} / \mathrm{kg}$ body weight) and treated with honey $(10 \%(\mathrm{w} / \mathrm{w})$ and / or nigella sativa oil $(2.5 \mathrm{ml} / \mathrm{kg}$ body weight). Statistical analysis (one-way ANOVA) indicated that, there was extremely high significant difference $(p<0.0001)$ among all groups.

\section{Discussion}

The human body is exposed nowadays to increasing attacks by toxic compounds in polluted air, industrially processed foods, alcohol and drug consumption that increase liver toxicity, leading to more and more severe cases of hepatic disorders (Andritoiu et al., 2014).Assessment of hematological parameters can be used to determine the extent deleterious effect of foreign compounds including acrylamide on the blood constituents of an animal. Such analysis is relevant to risk evaluation as the changes in the hematological system have higher predictive value for human toxicity, when the data are translated from animal studies (Olson et al., 2000). In the current study, ACR affects the hematological parameters of rats under study. Its known that, ACR is not only neurotoxic and carcinogenic but also causes damages to the erythrocyte membrane and generates the micro nucleated erythrocytes, as well as alters the blood viscosity parameters (Arihan et al., 2011). The present study showed that there was significant decrease $(\mathrm{P}<0.05)$ in hemoglobin content, $\mathrm{RBCs}$ number and of platelets count $(\mathrm{P}>0.05)$ but, there was increase with no significant difference $(\mathrm{P}>0.05)$ in number of WBCs. in rats drinking acrylamide compared with control group. There results of the present study agree with that of sharma and Jain,(2008) in which acrylamide induced a significant decrease in hemoglobin $(\mathrm{Hb})$, erythrocytes (RBCs), hematocrit (HCT) and lymphocyte levels of young female rats.

Tarskikh (2006) observed some changes in physiochemical characteristics of biological membranes, decrease in erythrocyte acid resistance and activation of lipid peroxidation
(LPO) at the early stage after ACR administration accompanied by a decrease in erythrocyte count. The present study revealed that $\mathrm{Hb}$ decreased significantly after oral administration of ACR as also reported by Barber et al. (2001) in which the ACR covalently binds to the cysteine residues and forms adducts with sulfhydryl groups on hemoglobin, resulting in the loss of heme part of hemoglobin molecules, hereby reducing the amount of $\mathrm{Hb}$ in the blood, which in turn may also be responsible for the anemic conditions as evident by the low level of RBCs observed in the present investigation (Sharma \& Jain, 2008). The present study also showed significant change in the total white blood cell count (WBCs) following ACR treatment. This change in total WBCs count suggests that ACR may be immunosuppressive. And this change could be due to their diminished production, redistribution from peripheral blood into the tissues or rapid destruction of WBCs as discussed by Debaun (2005).

Honey is composed of approximately $82.4 \%$ total carbohydrates which include mainly $38.5 \%$ fructose and $31 \%$ glucose. Other sugars like maltose, sucrose and others constitute $12.9 \%$ of its composition (Khan et al., 2007).

Experimental studies on honey have shown that honey is antiseptic, antimicrobial, antipyretic, anti-inflammatory, antiallergent, antitoxic, sedative, laxative, antianemic, antioxidant, healing and cleansing (external and internal), moisturizing and blood-purifying and stimulates immunity(Needham et al., 2009). At treatment, there was significant increase in the hemoglobin content and RBCs of honey-treated group of animals as compared to untreated rats but, values were significantly lower than control animals. Moreover, there was significant decrease in the WBCs and platelets count of honey-treated groups of animals as compared to untreated rats. (AlWaili et al., 2006) found that, acute blood loss causes elevation of white blood cells, lymphocyte percentage, and hemoglobin; the results are significant reduction in white blood cells and a significant elevation of hemoglobin are obtained after acute blood loss in rats on total food restriction with 50\% honey feeding. Honey administration tends to have stabilizing effects on hemoglobin, red blood cell counts. Furthermore, an increased in packed cell volume, mean corpuscular hemoglobin and white blood cell counts at $20 \%(\mathrm{v} / \mathrm{v})$ treated group corroborate the honey as an anti-anemic and immune-stimulant agent (Fiorani et al., 2006). There were also increased in platelet and decreased in mean cell 
volume and mean corpuscular hemoglobin concentration in a concentration dependent manner. This is in accordance of the fact that exclusive honey feeding significantly modifies the hematological parameters (Noori et al., 2006). Clinical and experimental researches have shown many therapeutic effects of NS extracts such as immunomodulator, anti-inflammatory and antitumour, antibacteria agents (Rogozhin et al., 2011; Alam et al., 2010).

Thymoquinone (TQ) is the main constituent of volatile oil from $N$. sativa seeds which has exhibited different properties in modern pharmacology including anti-inflammatory (Woo et al., 2012). These results agree with the present study in which there was significant increase in hemoglobin content, RBCs number and of platelets count but, there was decrease with in number of WBCs in rats drinking acrylamide and treated with Nigella sativa oil compared with rats drinking acrylamide only. It was reported that the fixed oil of NS and the derived thymoquinone inhibited eicosanoid generation in leukocytes and membrane lipid peroxidation (Houghton et al., 1995).

Tumor necrosis factor (TNF), have been shown to mediate tumor initiation, promotion, and progression (Moore et al., 1999). The pro inflammatory effect of TNF is linked to many diseases due to its ability to activate NF-kB (Sugarman et al., 1985). The present study showed that ACR causes an elevation in the level of TNF-alpha. However, treatment with honey and /or NS oil causes decrease of TNF level compared with rats drinking acrylamide only. Nigella sativa was documented to increase $\mathrm{T}$ helper cell and other leucocytes (Bamosa et al, 1997) and (ElKadi \& Kandil, 1986). It has potent antiinflammatory, pyrexic and analgesic effects (AlGhamdi, 2001) and (Houghton et al, 1995).

The mean level of $\mathrm{IL}-17$ in rats drinking acrylamide was increased significantly. After treatment with honey and NS oil, there was an extremely significant decrease $(\mathrm{P} 2<0.0001)$ compared with rats drinking acrylamide only.

IL-17 is cytokine has some biological activities, including induction of cytokines and chemokines involved in inflammatory responses (Iwakura, and Ishigame, 2006). Acrylamide toxicity causes inflammatory response. This response resulted in raising the level of IL-17 together with TNF-alpha as suggested by the present study. However the anti-inflammatory effect of honey and NS oil lead to the reduction of IL-17 and TNF-alpha levels in rats drinking acrylamide after treatment.
In conclusion, ACR causes inflammation leading to elevation of TNF and IL-17 levels, but after treatment with NS oil and/ or honey their levels were improved again. These results lead one to conclude that, this type of treatment follow an immune mediated root.

\section{References}

Ahmad, A., A. Husain, M. Mujeeb, S.A. Khan and A. KNajmi et al ( 2013) A review on therapeutic potential of Nigella sativa: A miracle herb. Asian Pacific J Tropical Biomed., 3: 337-352DOI: 10.1016/S2221-1691(13)60075-1.

Ajibola A, Chamunorwa JP, Erlwanger KH (2012) Nutraceutical values ofnatural honey and its contribution to human health and wealth. Nutr Metab (Lond) 9: 61.

Alam, M. M., M. Yasmin, et al. (2010). "Antibacterial activity of chloroform and ethanol extracts of black cumin seeds (Nigella sativa) against multi-drug resistant human pathogens under laboratory conditions" J Med Plant Res 4(18): 1901-1905.

Ali, B.H. and G. Blunden (2003) Pharmacological and toxicological properties of Nigella sativa Phytotherapy Res., 17: 299-305DOI: 10.1002/ptr.1309.

Al-Logmani, A. and T.A. Zari, (2011). Long-term effects of Nigella sativa L. oil on some physiological parameters in normal and streptozotocin-induced diabetic rats. J. Diabetes Mellitus, 1: 46-53DOI: 10.4236/jdm.2011.13007.

Al-Waili NS, Saloom KY, Akmal M, Al-Waili F, AlWaili TN, Al-Waili AN, Ali A.(2006) Honey ameliorates influence of hemorrhage and food restriction on renal and hepatic functions, and hematological and biochemical variables. Int J Food Sci Nutr. Aug-Sep;57(5-6):353-62.

Andritoiu CV, Ochiuz L, Andritoiu V, Popa M.(2014 )Effect of apitherapy formulations against carbon tetrachloride-induced toxicity in Wistar rats after three weeks of treatment. Molecules. Aug 29;19(9):13374-91.

Arihan, O., N.B. Seringec, E.I. Gurel and N.H. Dikmenoglu(2011) Effects of oral acrylamide intake on blood viscosity parameters in rats. Clin. Hemorheol. Microcircul., 47: 45-52.

Arriaga E, Navarro-Calvo AL, Díaz-Carbajal E (2011) Botanical characterization of Mexican honeys from a subtropical region (Oaxaca) based on pollen analysis. Grana 50: 40-45.

Bamosa AO, Ali BA, Sowayan SA. (1997) Effect of oral ingestion of Nigella sativa seed on some blood parameters. Saudi Pharm J.;5 (2-3):126-129. 
Barber, D.S., J.R. Hunt, M.F. Ehrich, E.J. Lehning and R.M. LoPachin, (2001). Metabolism, toxicokinetics and hemoglobin adduct formation in rats following subacute and subchronic acrylamide dosing. Neurotoxicology, 22: 341-353.

Beretta G, Gelmini F, Lodi V, Piazzalunga A, MaffeiFacino R(2010)Profile ofnitric oxide (NO) metabolites (nitrate, nitrite and $\mathrm{N}$-nitroso groups) in honeys ofdifferent botanical origin: nitrate accumulation as index of origin, quality and oftherapeutic opportunities. J Pharm Biomed Anal 53: 343-349.

Bogdanov S, Jurendic T, Sieber R, Gallmann P (2008) Honey for nutrition andhealth: a review. J Am CollNutr 27: 677-689.

Debaun MR (2005). Hydroxyurea as secondary prevention for stroke in

children with sickle cell anaemia, J. Pediatr., 147: 560561.

El-Kadi A, Kandil O. (1986) Effect of Nigella sativa (the black seed) on immunity, Proceeding of the 4th International Conference on Islamic Medicine, Kuwait. Bull Islamic Med. ;4:344-348.

Fiorani, M., Accorsi, A., Blasa. M.,Diamantini, G., and Piatti, E.(2006) Flavonoids from Italian multifloral honey reduce the extracellular ferricyanide in human red blood cells. J. Agric. Food Chem., 54: 8328-8334.

Gheldof N, Wang XH, Engeseth NJ (2002) Identification and quantification ofantioxidant components of honeys from various floral sources. J Agric Food Chem 50: 5870-5877.

Houghton PJ, Zarka R, De lasHeras B, Hoult JRS.( 1995). Fixed oil of Nigella sativa and derived thymoquinone inhibit eicosanoid generation in leukocytes and membrane lipid peroxidation. Planta Med 61: 33-36.

Iwakura, Y., and H. Ishigame. (2006). The IL-23/IL-17 axis in inflammation. J. Clin. Invest. 116: 1218 1222.

KeivanJamshidi, Afshin Zahedi (1999) AcrylamideInduced Acute Nephrotoxicity in Rats. International Scholarly and Scientific Research \& Innovation 2(4) 2015. scholar.waset.org/.13/23035

KeivanJamshidi, Afshin Zahedi ( 2015) AcrylamideInduced Acute Nephrotoxicity in Rats. International Scholarly and Scientific Research \& Innovation 2(4) scholar.waset.org/1999.13/23035.

Khan F.R., Abadin Z.U., Rauf N. (2007) Honey: nutritional and medicinal value. Int. J. Clin. Pract. ;61:1705-1707.

Krishnakumar $\mathrm{T}$ and Visvanathan $\mathrm{R}$ (2014).Acrylamide in Food Products: A Review.J Food Process Technol, 5:344.

Moore RJ, Owens DM, Stamp G, et al. Mice deficient in tumor necrosis factor-alpha are resistant to skin carcinogenesis. Nature Medicine. 1999;5(7):828831.

Needham AW. Health benefits of honey. 2008. [Last cited on 2009 Oct 12]. Available from: http://www.bees-

online.com/HealthBenefitsOfHoney.htm

Noori, S. A. W., Saloom, K. Y., Al-Waili, T. N., AlWaili, A. N., Akmal, M., Al-Waili, F. S., and AlWaili, H. N. (2006). Influence of various diet regimens on deterioration of hepatic function and hematological parameters following carbon tetrachloride: a potential protective role of natural honey. Nat. Prod. Res., 20: 1258-1264.

Olson H, Betton G, Robinson D, Thomas K, Monro A, Kolaja G, Lilly P,

Sanders J, Sipes G, Bracken W, Dorato M, Deun KV, Smith P,

Berger B, Heller A(2000)Concordance of toxicity of

pharmaceuticals in humans and in animals, Regul. Toxicol.

Pharmacol., 32(1): 56-67.

Rchid, H., H. Chevassus, R. Nmila, C. Guiral and P Petit et al ( 2004). Nigella sativa seed extracts enhance glucose-induced insulin release from ratisolated Langerhans islets. Fundamental Clinical Pharmacol., 18: 525-529.

Rogozhin, E. A., Y. I. Oshchepkova, et al. (2011). "Novel antifungal defensing from Nigella sativa L. seeds." Plant Physiol Biochem 49(2): 131-137.

Salih, B., T. Sipahi and E.O. Donmez ( 2009) Ancientnigella seeds from Boyal Höyük in northcentral Turkey. J. Ethnopharmacology, 124: 416420DOI: $10.1016 /$ j.jep.2009.05.039

Sharma, A. and J. Jain, (2008). Effects of oral exposure of acrylamide on plasma levels of thyroid hormones and haematological parameters in the Swiss albino mice. Asian J. Exp. Sci., 22: 317-324.

Sugarman BJ, Aggarwal BB, Hass PE. (1985).Recombinant human tumor necrosis factor$\alpha$ : effects on proliferation of normal and transformed cells in vitro. Science.; 230(4728):943-945.

Tarskikh, M.M., (2006). Damage to erythrocyte membranes as the mechanism for acrylate toxicity. Bull. Exp. Biol. Med., 142: 690-692.

Wang J, Li QX (2011) Chemical composition, characterization, and differentiation of honey botanical and geographical origins. Adv Food Nutr Res 62: 89-137.

White JW, Doner LW(1980).Honey composition and properties: Beekeeping in the United States. Agric Handbook 335: 82-91.

Woo CC, Kumar AP, Sethi G, Tan KHB. (2012).Thymoquinone: Potential cure for inflammatory disorders and cancer. Biochem Pharmacol. ;83:443-451. [PubMed]. 53: 511-516 


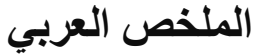

عنوان البحث: التأثير الوقائي لبعض المنتجات الطبيعية علي السمية المستحدثة بالأكر بيلاميد المين

قدري البكري، جمال عبد الله، محمد البهنساوي، لطفي حبق و العابد فايزة أبو بكر

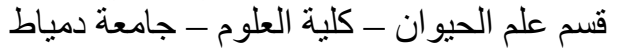

مقدمة: الأكريلاميا (ACR) هي مادة معروفة فى الصناعات تتلذخل فى عملية التمثيل الغذائى فى الكائن

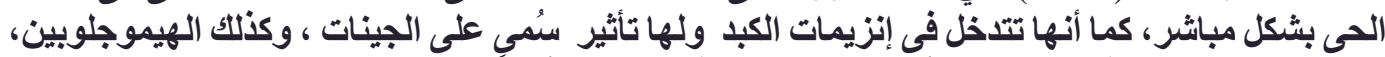

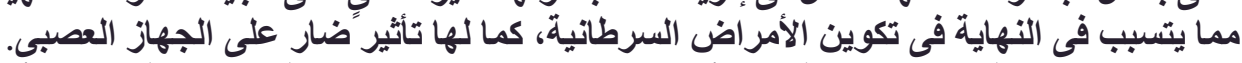

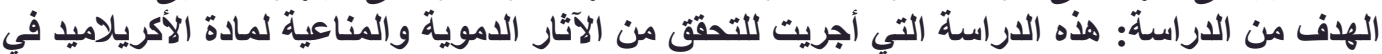

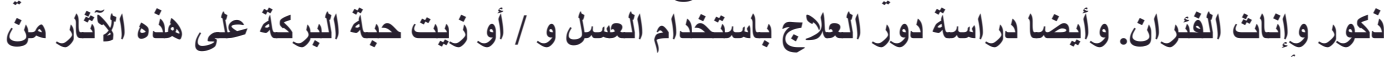

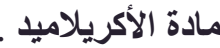

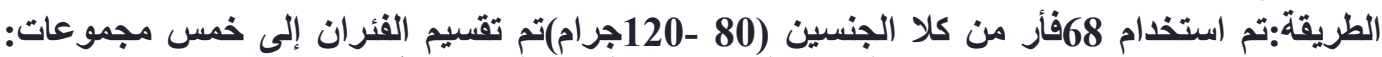

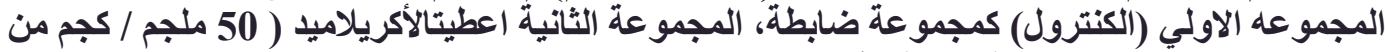

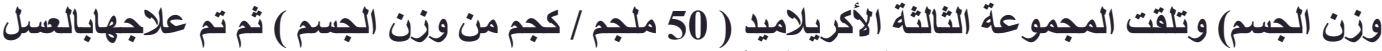

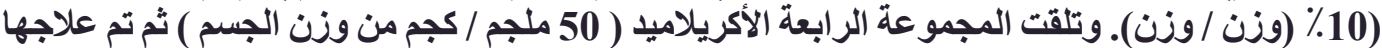

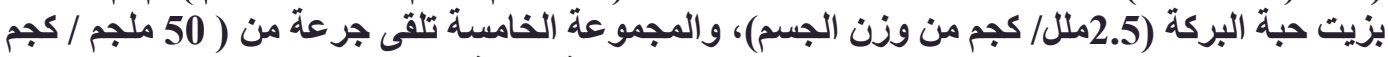

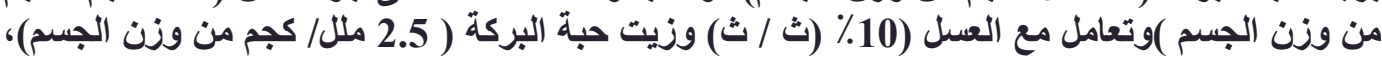

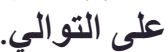

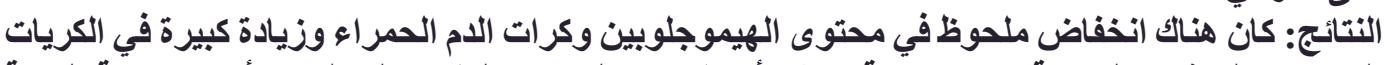

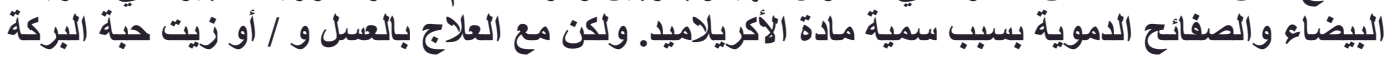

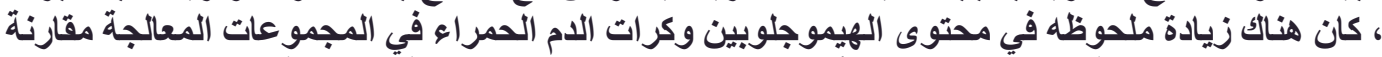

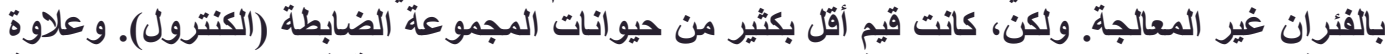

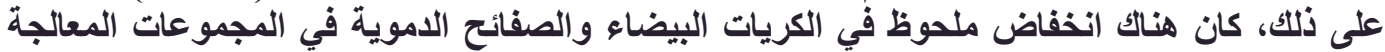

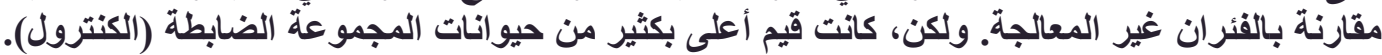

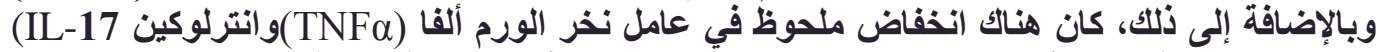

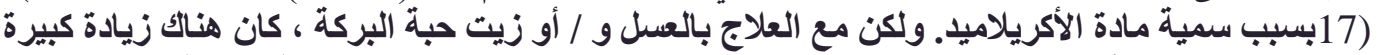

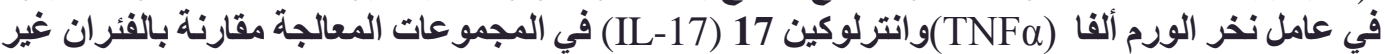

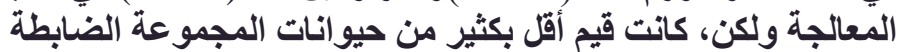

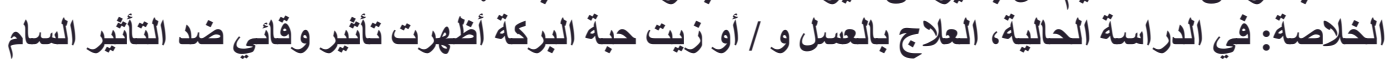

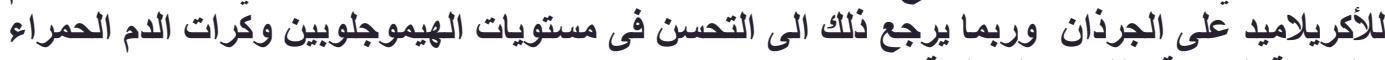
والمناعة الخاصة بالفئران المعالجة. 